Thorax (1976), 31, 685.

\title{
Pattern of total and regional lung function in subjects with bronchoconstriction induced by 15-me $\mathrm{PGF}_{2 a}{ }^{1}$
}

\author{
L. HESLET ANDERSEN and N. J. SECHER \\ Departments of Clinical Physiology and Gynaecology and Obstetrics, Odense University Hospital, \\ DK-5000 Odense, Denmark
}

\begin{abstract}
Andersen, L. H. and Secher, N. J. (1976). Thorax, 31, 685-692. Pattern of total and regional lung function in subjects with bronchoconstriction induced by 15 -me $\mathbf{P G F}_{2 a}$. Closing volume (single breath nitrogen test), regional ventilation and perfusion (using intravenous xenon-133), and total lung function (TLC, VC, and $\mathrm{FEV}_{1}$ ) were measured before and after intramuscular administration of $250 \mu \mathrm{g}$ 15-methyl prostaglandin $\mathrm{F}_{2 a}\left(15-\mathrm{me} \mathrm{PGF}_{2 a}\right)$ in 10 healthy women. The cardiac output was measured with the Minnesota impedance cardiograph model 304A and the transthoracic impedance was used as an expression of the thoracicfluid volume. The slope of the alveolar plateau on the closing volume tracing showed a $271 \%$ increase 20 minutes after the prostaglandin administration, at which time the closing volume per cent $(\mathrm{CV} \%)$ had decreased $(\mathrm{P}<0.01)$ and the closing capacity $(\mathrm{CC} \%)$ had increased $(\mathrm{P}<0.05)$. Vital capacity $(\mathrm{VC})$ decreased $(P<0.01)$, residual volume $(R V)$ increased $(P<0.01)$, and the total lung capacity (TLC) remained unchanged. The maximal decrease $(9 \%)$ in $\mathrm{FEV}_{1}$ was seen after 20 minutes. All these measurements except the slope of the alveolar plateau returned to control levels after $60 \mathrm{~min}$ utes. The redistribution of regional ventilation was more pronounced than that of the regional pulmonary blood flow. No change was observed in cardiac output and transthoracic impedance. None of the patients experienced any dyspnoea. Our results are consistent with a more pronounced effect of prostaglandin $F_{2 a}$ on the small airways (the alveolar plateau) than on the larger airways $\left(F E V_{1}\right)$. In cases where an increase in the slope of the alveolar plateau is observed, the closing volume per cent should not be used as a measurement of the lung disease. It is concluded that the single breath nitrogen test $\left(\mathrm{N}_{2}\right.$ closing volume) is more sensitive than the conventional tests.
\end{abstract}

The prostaglandins (PG) have been shown to produce a pronounced effect on the pulmonary circulation in animal studies (Alpert et al., 1973; Kadowitz, Joiner, and Hyman, 1974). Pronounced bronchoconstrictive effect has been seen in human studies after administration of prostaglandin $\mathrm{F}_{2_{a}}\left(\mathrm{PGF}_{\mathbf{2}_{a}}\right)$ (Smith, 1973). Various stimuli have been shown to release prostaglandin from lung tissue (Shaw and Moser, 1975) and it has been suggested that the local release of prostaglandins may influence the ventilation/ perfusion ratio (Piper and Vane, 1971). The purpose of the present investigation was to study the sensitivity and changes in the single breath nitrogen test measurements (slope of phase III, closing volume per

1 A part of this study was presented at the Symposium on Closing Volume, Odense, Denmark, 20-21 October 1975 cent $(\mathrm{CV} \%)$, and closing capacity $(\mathrm{CC} \%))$ and the conventional static and dynamic spirometric tests after the administration of $\mathrm{PGF}_{\mathbf{2}_{\alpha}}$. Radiospirometry by intravenous administration of xenon-133 (133Xe) was performed for further evaluation of the changes induced by the 15-methyl derivative of $\mathrm{PGF}_{2_{a}}$ (15-me PGF $_{2 a}$ ).

Prostaglandins are being widely used for induction of labour and abortion. For this reason it is important to evaluate the effect of $15-\mathrm{me} \mathrm{PGF}_{2 a}$ on the pulmonary circulation and ventilation in humans, as these agents may be contraindicated in patients with cardiopulmonary diseases.

MATERIAL AND METHODS

The aim of the present study, the experimental 
procedure, and possible side effects of the drug were explained in detail to the subjects, aged 22-36 years. Thereafter the 10 subjects consented to take part in the investigation. There was no history or physical sign of cardiopulmonary abnormality in any of these subjects, neither was any of them a heavy smoker ( $<10$ cigarettes per day).

Closing volume was measured by the single breath nitrogen test modified by Mansell, Bryan, and Levison (1972), Oxhøj and Bake (1974), and carefully described by Rasmussen, Sølvsteen, and Andersen (1975). The measuring system consists of a bag in box' system, a nitrogen analyser with remote measuring head (Godart Nitrograph type 18121), and a water-sealed spirometer fitted with an analogue potentiometer, the output of which (volume (X-axis)) was registered versus the output from the nitrogen analyser (nitrogen per cent (Y-axis)) on an XYrecorder (Hewlett-Packard 7054A). The apparatus had a dead space of $150 \mathrm{ml}$ and external resistances in the inspiratory and the expiratory tubing in order to limit the inspiratory and expiratory flow rates to less than 0.5 litres per second. When the subject is seated and fitted with a mouthpiece and noseclamp, the system is operated by five solenoid valves directing the respiratory flow. The subject exhales maximally to the atmosphere, signals the operator, and is switched on to the apparatus, after which maximal inspiration is carried out immediately followed (without breath-holding) by a maximal expiration. An interval of 5 minutes is interposed in order to restore alveolar nitrogen concentration (FAN2). $\mathbb{D}$ Nitrogen concentration versus volume are registered during both inspiration and expiration; this gives a typical tracing (Fig. 1, control level). It is possible in $\vec{\circ}$ this way to register endexpiratory alveolar nitrogen $\overrightarrow{\vec{\omega}}$ concentration (FAN2) and both inspiratory and $\stackrel{\omega}{\omega}$ expiratory vital capacity $\left(\mathrm{VC}_{1}\right.$ and $\left.\mathrm{VC}_{e}\right)$, thus ensuring $\overrightarrow{\vec{x}}$ the delivery of the nitrogen bolus near residual volume (RV). The slope of the best fitting line (slope III) drawn through the largest possible part of the alveolar plateau (phase III) represents the degree of of uneven alveolar ventilation (Buist and Ross, 0 1973b). The place at which the tracing finally departs from this line is believed to represent the onset of $\vec{\sigma}$

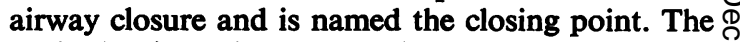
expired volume from this point until the end of the tracing is named closing volume or phase IV.

The only tracings accepted were within the range: $-10 \% \leq\left(\mathrm{VC}_{1}-\mathrm{VC}_{\mathrm{e}}\right) \times 100 / \mathrm{VC} \leq+5 \%$ where VC is the largest of $\mathrm{VC}_{\mathrm{i}}$ and $\mathrm{VC}_{\mathrm{e}}$. Closing oे volume was expressed as:

and

$$
\text { (a) } \mathrm{CV} \%=\text { phase IV } \times 100 / \mathrm{VC}
$$

$$
\text { (b) } \begin{aligned}
\mathrm{CC} \%= & \text { (phase IV (BTPS) }+\mathrm{RV} \text { (BTPS) }) \\
& \times 100 / \text { TLC (BTPS) }
\end{aligned}
$$
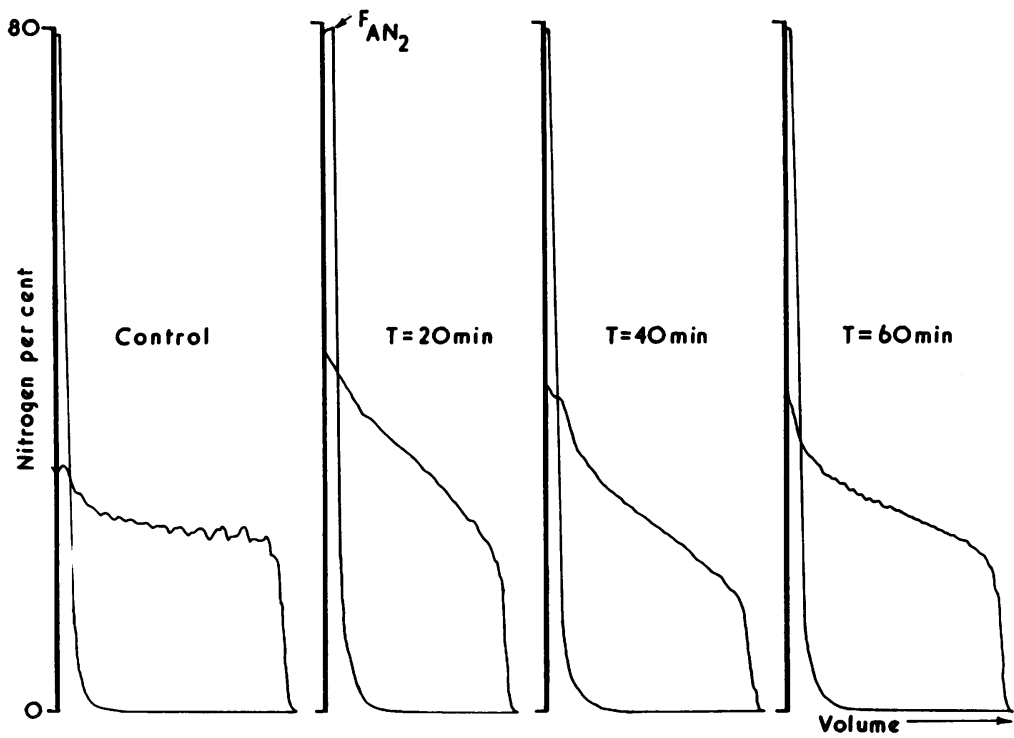

FIG. 1. Pattern of changes in one subject in the closing volume tracings before and after intramuscular administration of 15-me PGF $2 a . \mathrm{N}_{2} \%$ is depicted on the ordinate and inspired and expired volume on the abscissa. 
where

$$
R V=T L C-V C \text {. }
$$

TLC was derived from the analysis of a single expiration:

$$
\begin{aligned}
& T L C=\left(\left(V_{1}-V_{D A}\right) \times F_{A N_{2}}-V_{D S} \times F_{A} N_{2}\right) / \\
& \left(\mathrm{FAN}_{2}-\mathrm{FANN}_{2}\right)
\end{aligned}
$$

where $V D A=$ apparatus dead space $=150 \mathrm{ml}$

VDS $=$ subject dead space $=150 \mathrm{ml}$

$\mathrm{FAN}_{2}=$ the endexpiratory alveolar nitrogen concentration.

$\mathrm{FAN}_{2}=$ mean alveolar nitrogen concentration $=$ $\mathrm{A} /(\mathrm{VCe}-150)$

where $\mathbf{A}=$ area under the expired nitrogen concentration versus volume curve in $\mathrm{ml} \times$ nitrogen concentration.

Radiospirometry using ${ }^{133} \mathrm{Xe}$ was introduced by Ball et al. (1962).

The regional blood flow of the lung and the regional ventilation were studied according to the method described by Andersen, Johansen, and Hyldebrandt (1976) and Andersen and Rasmussen (1975). Four horizontal collimated detectors were placed in a vertical row over the back of the right lung field. The detector diameter was $4.5 \mathrm{~cm}$ and the distance between the apical and basal detectors was $18 \mathrm{~cm}$. The top of the apical detector was placed below the line between the right clavicle and the upper edge of the right scapula, after inspiration to TLC. ${ }^{133} \mathrm{Xe}$ was injected after 20 minutes in the sitting position in doses of $0.7 \mathrm{mCi}$ and flushed through a right antecubital vein with $10 \mathrm{ml}$ saline during breath-holding with open glottis at TLC. The perfusion height $(\mathrm{H})$-deflection from base line during breath-holding-is proportional to the regional pulmonary blood flow. After injection of ${ }^{133} \mathrm{Xe}$ rebreathing was carried out into a closed system, consisting of a $\mathrm{CO}_{2}$ absorber and a 4-litre rubber bag filled with oxygen. After equilibration (about $2 \mathrm{~min}$ ), as judged by a constant relationship between the four zones, three inspirations to TLC were performed producing a mean rebreathing height (R) proportional to the number of alveoli in the respective detector fields. The regional perfusion for each of the four detectors was expressed as the perfusion index: $(\mathrm{PI})_{\mathrm{n}}=\left(\mathrm{H}_{\mathrm{n}} /\left(\mathrm{H}_{1}+\mathrm{H}_{2}+\mathrm{H}_{3}+\mathrm{H}_{4}\right)\right)$ / $\mathbf{R}_{\mathbf{n}}\left(\mathbf{R}_{\mathbf{1}}+\mathbf{R}_{\mathbf{2}}+\mathbf{R}_{3}+\mathbf{R}_{4}\right)$ ) where $\mathbf{n}=$ detector number $=$ $1,2,3$, or 4 . Detector 1 refers to the apical and detector 4 to basal lung section. The units of PI are therefore: Flow (arbitrary units) per alveolus. The regional ventilation was obtained by analysing the regional washout curves during normal breathing after breath-holding at TLC.

The curves consist after subtraction of background level of washout by means of alveolar ventilation, apart from the tail end of the curve; here there is a build-up of radioactivity in lung tissue and chest wall during the test and in addition xenon from the systemic circulation begins to recirculate.

The washout curves were therefore analysed in a manner that eliminated factors other than the pure washout from the alveoli. The washout curves were depicted in semilogarithmic plots. It is possible by means of the rate constant $\left(\mathrm{k}_{1} \mathrm{~min}^{-1}\right)$ and the intersection point $\left(a_{1} \mathrm{Cps}\right)$ to calculate the exponential function $\left(a_{1} \cdot e^{-k_{1}} \cdot t\right)$ covering the tail part of the curve. The residual part of the curve is treated in the same way after subtraction of $a_{1} \cdot e^{-k_{1}} \cdot t$ from the original count rates; this gives rise to a second rate constant $\left(\mathrm{k}_{2} \mathrm{~min}^{-1}\right)$, which reflects the regional alveolar ventilation (peeling-off technique).

In order to eliminate the influence of the breathing frequency, the rate constants for each detector $\left(k_{2}, n\right)$ are calculated as a per cent of the total in each trial $\left(\mathbf{V n}=\right.$ ventilation index $=\mathbf{k}_{2, \mathbf{n}} \cdot 100 /\left(\mathbf{k}_{2,1}+\mathbf{k}_{2,2}+\right.$ $k_{2,3}+K_{2,4}$ ), where $n=$ detector number $=1,2,3$ or 4 ).

Forced expiratory volume $\left(\mathrm{FEV}_{1}\right)$ was measured with a pneumotachograph (Godart) and a Fleisch tube.

The cardiac output and the transthoracic electric impedance $\left(Z_{0}\right)$ were measured by the Minnesota impedance cardiograph model $304 \mathrm{~A}$ as designed by Kubicek et al. (1966). $Z_{0}$ is a function of thoracic fluid volume (Luepker, Michael, and Warbasse (1973).

PROCEDURE OF THE INVESTIGATION Three acceptable closing volume tracings were obtained at control level (before the administration of 15-me $\mathrm{PGF}_{2 a}$ ); these were followed by three measurements of FEV 1 , after which regional ventilation/perfusion was studied twice, followed by one rebreathing manoeuvre. One closing volume tracing was obtained five minutes after $250 \mu \mathrm{g}$ 15-me $\mathrm{PGF}_{2_{a}}$ had been administered in the gluteal muscle. One closing volume tracing was taken followed by two measurements of $\mathrm{FEV}_{1}$ and one study of the regional ventilation and perfusion and finally by one more closing volume tracing at 20 , 40 , and 60 minutes. Cardiac output was measured in four patients with the impedance method before and after the administration of $15-$ me GGF $_{2_{a}}$, and in one patient the radial artery was punctured and samples were removed for blood gas analysis at control level and 20 minutes after the administration of 15 -me $\mathrm{PGF}_{2 a}$.

The mean values of the above measurements after the administration of $\mathrm{PGF}_{2 a}$ were compared with those obtained before the administration (control values) using the Wilcoxon matched-pairs signedranks test (Siegel, 1956). 


\section{RESULTS}

Nausea and menstrual cramps occurred in all patients, but none of the patients experienced any cardiopulmonary symptoms, in particular no dyspnoea. Further, no change of the character of the normal breath sounds, as evaluated by auscultation of the chest, occurred. All the patients passed loose stools within the first two hours of the administration of 15-me $\mathrm{PGF}_{2_{\alpha}}$.

The results of the single-breath nitrogen test and forced expiratory manoeuvres are shown in Table $I$. A decrease in $\mathrm{CV} \%$ was found 20 minutes after the administration of $15-$ me $^{P^{2}} \mathrm{FF}_{2 a}$ in spite of a concomitant decrease in vital capacity $(\mathrm{P}<0.01)$. This is in agreement with the findings of a decrease in the absolute value of phase IV in $\mathrm{mm}(\mathrm{P}<0.01)$, whereas $\mathrm{CC} \%$ increased $(\mathrm{P}<0.05)$. The changes in $\mathrm{CV} \%$ and $\mathrm{CC} \%$ were only slight, whereas the change in the slope of phase III showed a pronounced increase $(271 \%)(\mathrm{P}<0.01)$. Residual volume and residual volume in per cent of TLC (RV/TLC \%) both showed a significant increase $(P<0.01)$, whereas TLC did not change $(P>0.05)$. A decrease of $9 \%$ in $\mathrm{FEV}_{1}$ at 20 minutes was seen $(P<0.05)$. The above measurements from the single-breath nitrogen test together with the subdivisions of lung volume and $\mathrm{FEV}_{1}$ returned to control levels after $\mathbf{4 0}$ minutes except for the values of the slope of the alveolar plateau (slope III) which were still raised at 60 minutes $(P<0.05)$. The result of the qualitative analysis of the closing volume curves (Fig. 1) showed lack of cardiogenic oscillations $(P<0.05)$ and curvilinear take-off from the alveolar plateau $(P<0.05)$ at 20 minutes. The cardiac output and $Z_{0}$ showed no change after the administration of 15-me $\mathrm{PGF}_{2 a}$ in four subjects. The arterial oxygento tension of one subject fell from 89 (control) to 73 음 mmHg 20 minutes after 15 -me PGF $_{2_{a}}$, whereas arterial carbon dioxide tension $\left(\mathrm{PaCO}_{2}\right)$ (31 to $30 \AA$ $\mathrm{mmHg})$ and $\mathrm{pH}(7.43$ to 7.43$)$ remained unchanged.

The results of the radiospirometry (regional per- ${ }^{\text {s }}$ fusion and ventilation) are shown in Table II. The $\vec{O}$ control values of regional perfusion and ventilation $\overrightarrow{\vec{H}}$ showed a positive gradient from the apical to the basal $\stackrel{\omega}{\mathcal{D}}$ lung section. A redistribution of both regional $\overrightarrow{2}$ ventilation and perfusion was seen after the admini- $-\dot{\omega}$ stration of 15-me PGF $_{2 a}$ (Figs. 2 and 3). A significant increase of perfusion in the upper part of the lung. $\left(P_{1}\right.$ and $\left.P_{2}\right)(P<0.01)$ and a decrease in the lowero $\left(P_{3}\right.$ and $\left.P_{4}\right)$ was found $(P<0.05)$ after 20 minutes.o After 40 and 60 minutes there was no significant ${ }_{-}^{3}$ change in the distribution of regional perfusion as compared to control values $(P>0.05)$. At 20 minutes $a \stackrel{\Phi}{\Phi}$ positive perfusion gradient from apical to basal lung $\frac{\mathbb{S}}{3}$ section was still present, which is in contrast to the changes seen in the regional ventilation where the apical ventilation exceeded the basal ventilation. At $\overrightarrow{0}$ 20,40 , and 60 minutes there was a significant decrease $\sigma$ in basal ventilation $\left(\mathrm{V}_{3}\right.$ and $\left.\mathrm{V}_{4}\right)$ compared to controlo values.

\section{DISCUSSION}

Our findings of a significant decrease in $\mathrm{FEV}_{1}$ of $9 \%$ indicate that bronchoconstriction is induced after the administration of $15-$ me $\mathrm{PGF}_{2_{a}}$. This abnormality of lung function is further demonstrated by $271 \%$ increase in unevenness of distribution of alveolar ventilation (slope of the alveolar plateau), an increase in residual volume, a decrease in vital capacity, and

T A B L E I

PULMONARY FUNCTION BEFORE AND AFTER 15-me PGF $2 a$

\begin{tabular}{|c|c|c|c|c|c|c|c|c|c|}
\hline & $\mathrm{CV} \%$ & $\begin{array}{c}\text { Phase IV } \\
(\mathrm{mm})\end{array}$ & $\mathrm{CC} \%$ & $\begin{array}{c}\text { Slope III } \\
\left(\% \mathrm{~N}_{2} / 1 \mathrm{BTPS}\right)\end{array}$ & $\begin{array}{c}\mathrm{VC} \\
\text { (ml B } \mathrm{CPS})\end{array}$ & $\begin{array}{c}\text { TLC } \\
\text { (ml B BPS })\end{array}$ & $\begin{array}{c}\mathrm{RV} \\
\text { (ml BTPS) }\end{array}$ & $\mathrm{RV} / \mathrm{TLC} \%$ & $\underset{(\mathrm{ml} \mathrm{BTPS}}{\mathrm{FEV}_{1}}$ \\
\hline $\begin{array}{c}\text { Control } \\
\text { Mean } \\
\text { SD } \\
\text { N }\end{array}$ & $\begin{array}{l}14.5 \\
7.6 \\
10\end{array}$ & $\begin{array}{l}12 \cdot 6 \\
6 \cdot 3 \\
10\end{array}$ & $\begin{array}{l}35 \cdot 1 \\
6 \cdot 7 \\
10\end{array}$ & $\begin{array}{l}1.24 \\
0.64 \\
10\end{array}$ & $\begin{array}{c}3435 \\
390 \\
10\end{array}$ & $\begin{array}{r}4513 \\
482 \\
10\end{array}$ & $\begin{array}{r}1071 \\
226 \\
10\end{array}$ & $\begin{array}{c}23 \cdot 6 \\
4 \cdot 2 \\
10\end{array}$ & $\begin{array}{r}3075 \\
377 \\
8\end{array}$ \\
\hline $\begin{array}{c}5 \min _{\text {Mean }} \\
\text { SD } \\
\text { N }\end{array}$ & $\begin{array}{c}12 \cdot 4 \\
4 \cdot 2 \\
7\end{array}$ & $\begin{array}{c}10 \cdot 4 \\
3 \cdot 8 \\
7\end{array}$ & $\begin{array}{c}35 \cdot 7 \\
5 \cdot 4 \\
7\end{array}$ & $\begin{array}{l}1.42 \\
0.97 \\
7\end{array}$ & $\begin{array}{r}3434 \\
450 \\
7\end{array}$ & $\begin{array}{r}4669 \\
472 \\
7\end{array}$ & $\begin{array}{r}1236 \\
272 \\
7\end{array}$ & $\begin{array}{r}26 \cdot 6 \\
5 \cdot 6 \\
7\end{array}$ & = \\
\hline $\begin{array}{c}20 \text { min } \\
\text { Mean } \\
\text { SD } \\
\text { N }\end{array}$ & $\begin{array}{c}11 \cdot 8 * \\
6.4 \\
10\end{array}$ & $\begin{array}{l}8 \cdot 8^{* * *} \\
4 \cdot 8 \\
10\end{array}$ & $\begin{array}{l}38 \cdot 5 * \\
5 \cdot 6 \\
10\end{array}$ & $\begin{array}{l}4 \cdot 61^{* *} \\
2 \cdot 38 \\
10^{* *}\end{array}$ & $\begin{array}{c}3054^{* * *} \\
517 \\
10\end{array}$ & $\begin{array}{r}4358 \\
549 \\
10\end{array}$ & $\begin{array}{c}1306 * * \\
234 \\
10\end{array}$ & $\begin{array}{l}30 \cdot 2 * * \\
4 \cdot 5 \\
10\end{array}$ & $\begin{array}{c}2790 * \\
453 \\
8\end{array}$ \\
\hline $\begin{array}{l}40 \text { min } \\
\text { SD } \\
\text { S }\end{array}$ & $\begin{array}{c}12 \cdot 8 \\
5 \cdot 3 \\
7\end{array}$ & $\begin{array}{c}10 \cdot 2 \\
3.9 \\
7\end{array}$ & $\begin{array}{c}36 \cdot 7 \\
5 \cdot 2 \\
7\end{array}$ & $\begin{array}{l}4 \cdot 00^{*} \\
2 \cdot 08 \\
7\end{array}$ & $\begin{array}{r}3400 \\
533 \\
7\end{array}$ & $\begin{array}{r}4487 \\
584 \\
7\end{array}$ & $\begin{array}{r}1228 \\
278 \\
7\end{array}$ & $\begin{array}{c}27 \cdot 3 \\
4.9 \\
7\end{array}$ & $\begin{array}{r}3008 \\
360 \\
6\end{array}$ \\
\hline $\begin{array}{l}\text { Mean } \\
\text { SD }\end{array}$ & $\begin{array}{l}12 \cdot 1 \\
5 \cdot 4 \\
6\end{array}$ & $\begin{array}{c}10.6 \\
4.5 \\
6\end{array}$ & $\begin{array}{c}33 \cdot 9 \\
5.0 \\
6\end{array}$ & $\begin{array}{l}2.02 * \\
1.59 \\
6\end{array}$ & $\begin{array}{r}3530 \\
434 \\
6\end{array}$ & $\begin{array}{r}4685 \\
482 \\
6\end{array}$ & $\begin{array}{r}1156 \\
290 \\
6\end{array}$ & $\begin{array}{c}24.5 \\
5.7 \\
6\end{array}$ & $\begin{array}{r}3093 \\
371 \\
6\end{array}$ \\
\hline
\end{tabular}


T A B L E I I

REGIONAL PERFUSION (FLOW/ALVEOLUS) AND REGIONAL VENTILATION BEFORE AND AFTER 15-me PGF ${ }_{2} a$

\begin{tabular}{|c|c|c|c|c|c|c|c|c|}
\hline & \multicolumn{4}{|c|}{ Perfusion Index } & \multicolumn{4}{|c|}{ Ventilation Index } \\
\hline & $\mathbf{P}_{1}$ & $\mathbf{P}_{2}$ & $P_{3}$ & P. & $\mathrm{V}_{1}$ & $\mathrm{~V}_{2}$ & $\mathrm{~V}_{3}$ & $V_{4}$ \\
\hline $\begin{array}{l}\text { Control values } \\
\text { Mean } \\
\text { SD } \\
20 \text { min }\end{array}$ & $\begin{array}{l}0.606 \\
0.073\end{array}$ & $\begin{array}{l}0 \cdot 790 \\
0.032\end{array}$ & $\begin{array}{l}1 \cdot 118 \\
0 \cdot 049\end{array}$ & $\begin{array}{l}1 \cdot 275 \\
0 \cdot 090\end{array}$ & $\begin{array}{r}17 \cdot 0 \\
4 \cdot 6\end{array}$ & $\begin{array}{r}23 \cdot 9 \\
1 \cdot 6\end{array}$ & $\begin{array}{r}26 \cdot 6 \\
1 \cdot 6\end{array}$ & $\begin{array}{r}32 \cdot 5 \\
3 \cdot 8\end{array}$ \\
\hline $\begin{array}{l}\text { Mean } \\
\text { SD } \\
40 \mathrm{~min}\end{array}$ & $\begin{array}{l}0 \cdot 709 * * \\
0.149\end{array}$ & $\begin{array}{l}0 \cdot 895^{* *} \\
0 \cdot 114\end{array}$ & $\begin{array}{l}1 \cdot 100^{*} \\
0 \cdot 082\end{array}$ & $\begin{array}{l}1 \cdot 135^{*} \\
0 \cdot 216\end{array}$ & $\begin{array}{r}24 \cdot 9 \\
4 \cdot 6\end{array}$ & $\begin{array}{l}26 \cdot 9 \\
10 \cdot 2\end{array}$ & $\begin{array}{l}24 \cdot 4^{* *} \\
2 \cdot 9\end{array}$ & $\begin{array}{c}23 \cdot 9 * * \\
7 \cdot 7\end{array}$ \\
\hline $\begin{array}{l}\text { Mean } \\
\text { SD } \\
60 \text { min }\end{array}$ & $\begin{array}{l}0 \cdot 654 \\
0.088\end{array}$ & $\begin{array}{l}0 \cdot 814 \\
0 \cdot 102\end{array}$ & $\begin{array}{l}1 \cdot 145 \\
0 \cdot 064\end{array}$ & $\begin{array}{l}1 \cdot 189 \\
0 \cdot 158\end{array}$ & $\begin{array}{r}23 \cdot 1 \\
2 \cdot 7\end{array}$ & $\begin{array}{r}22 \cdot 3 \\
2 \cdot 3\end{array}$ & $\begin{array}{c}25 \cdot 8 * \\
1 \cdot 4\end{array}$ & $\begin{array}{c}28 \cdot 9 * \\
3 \cdot 7\end{array}$ \\
\hline $\begin{array}{l}\text { Mean } \\
\text { SD }\end{array}$ & $\begin{array}{l}0.604 \\
0.091\end{array}$ & $\begin{array}{l}0.890 \\
0.088\end{array}$ & $\begin{array}{l}1 \cdot 124 \\
0 \cdot 072\end{array}$ & $\begin{array}{l}1 \cdot 229 \\
0 \cdot 162\end{array}$ & $\begin{array}{r}18 \cdot 7 \\
3 \cdot 3\end{array}$ & $\begin{array}{r}27 \cdot 3 \\
4 \cdot 2\end{array}$ & $\begin{array}{c}23 \cdot 9 * \\
1 \cdot 1\end{array}$ & $\begin{array}{c}27 \cdot 7^{*} \\
2 \cdot 6\end{array}$ \\
\hline
\end{tabular}

$\mathbf{P}=$ index of perfusion (flow/alveolus)

$\mathbf{V}=$ index of ventilation in per cent of total

Index numbers refer to detector numbers: $1=$ apical and $4=$ basal lung section.

$* P<0.05$.

$* * 0.01$

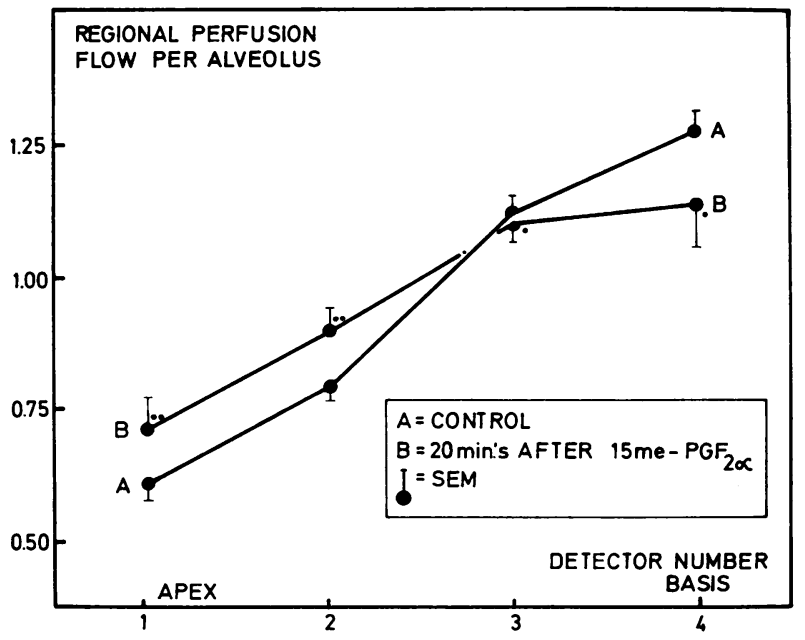

FIG. 2. Distribution of mean values of regional perfusion (flow/alveolus) in the sitting position before and after intramuscular 15-me $P G F_{2 a}$. A denotes resting perfusion values and $B$ denotes perfusion distribution 20 minutes after administration of intramuscular 15-me PGF 2 .

in one subject, a decrease in arterial oxygen tension. The slope of the alveolar plateau or the unevenness of alveolar ventilation was the most sensitive measurement in spite of the reproducibility of control values being $15 \%$, which is greater than that of $F E V_{1}$; the latter was $1 \%(P<0.01)$. In addition, the slope of phase III revealed the greatest changes. Finally, the slope of the alveolar plateau showed the longest duration of abnormal values.

The increase in slope of the alveolar plateau can be explained by stratified and/or regional inhomogeneity (Buist and Ross, 1973b). The marked decrease in basal ventilation throughout the study indicates that the maldistribution of alveolar ventilation must be due mainly to a decrease of ventilation in the basal lung sections, giving rise to regional inhomogeneity.

The closing volume increased after histamineinduced bronchoconstriction, as measured by the bolus method, whereas it decreased with the nitrogen method. This was explained by the inability of the nitrogen method to establish a concentration gradient in cases of 'air trapping' (Benson, Newberg, and Jones, 1975). Our method of measuring closing volume is a modified bolus technique (Oxhøj and Bake, 


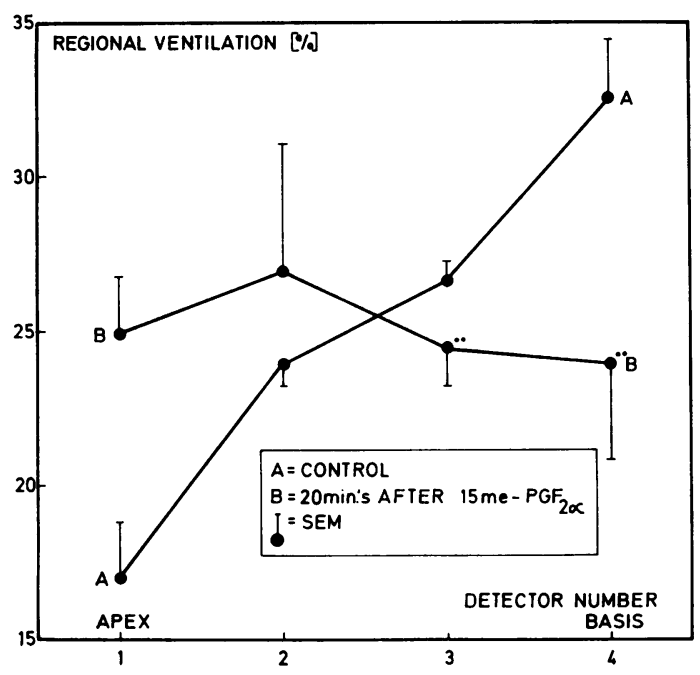

FIG. 3. Distribution of the mean values of regional ventilation before and after intramuscular 15-me $P G F_{2 a}$. $A$ denotes resting values and $B$ ventilation distribution 20 minutes after administration of 15-me PGF $F_{2 a}$. Detectors 3 and 4 correspond to lung base. ** Denotes significant difference $(\mathrm{P}<0.01)$.

1974); a dead space within the apparatus of $150 \mathrm{ml}$ when added to the anatomic dead space gives a nitrogen bolus of $300 \mathrm{ml}$; thus, an increase in closing volume would be expected. However, we found a decrease in closing volume after the induction of bronchoconstriction. A concomitant increase in the slope of the alveolar plateau was found similar to that seen after acetylcholine-induced bronchoconstriction when using the single-breath oxygen test (Stanescu et al., 1968). The increase in the degree of uneven ventilation could thus obscure a premature airway closure. The influence of methodological 'noise' is less pronounced when using a pure bolus method, as the tise of the alveolar plateau is smaller in persons with uneven ventilation. According to Buist and Ross (1973b), a simultaneous increase in closing volume per cent and slope of alveolar plateau is seen in the early stage of chronic airways obstruction. On the contrary, we have found a decrease in closing volume when the slope of the alveolar plateau increases. Thus, when a pathological increase in the slope of the alveolar plateau is present, low values of phase IV or closing volume could be misleading.

Several factors influence the phenomenon of airway closure, ie, changes in thoracic blood volume, peribronchial oedema, and changes in bronchial muscle tone and elastic recoil of the lungs
(Andersen et al., 1974). Our findings of ant unchanged $\mathrm{Z}_{0}$ suggest that it is unlikely that inter등 stitial oedema or a change in thoracic blood volumen plays any significant role in the present study. A considerable decrease in basal ventilation as observed in this investigation could suggest early airway closure inf? the dependent parts of the lung in agreement with the $\vec{\circ}$ findings of Benson et al. (1975) when using the bolus method. The findings of the decrease in $\mathrm{CV} \%$ in our study could be explained by a more even distribution of the inspired oxygen to the apical and middle lung sections, obliterating the apical/basal nitrogenconcentration gradient necessary for detection of early onset of airway closure.

On the other hand, the obliteration of the cardios genic oscillations of the alveolar plateau and the curvilinear take-off has been considered an indicator of chronic airways obstruction (Benson and Mansell 1975). The changes induced after $15-\mathrm{me} \mathrm{PGF}_{2_{a}}$ mighe thus be caused by an increase in smooth muscle tone्ट in the small airways, leading to a decreased tendency to airway closure; this would explain the decrease ino $\mathrm{CV} \%$ in our study. Should this be the case the in creased closing volume found by the bolus method could be an artefact.

When subdivisions of lung volume are estimated with the gas dilution method, there is a danger of underestimation due to the possible development of non or poorly ventilated areas of the lung (Buist and Ross, 1973a). In spite of this an increase in residua volume was found in all our patients. Increased residual volume without a concomitant increase in total lung capacity was found after provoked asthma using either the gas dilution method (Woolcock et al., 1971) or body plethysmography (Lovejoy et al. 1961; Stanescu, Frans, and Brasseur, 1973; Cade et al., 1971); this agrees with our findings. The increase in residual volume could be caused by ani increase in the amount of trapped gas in the lung, ie non-communicating alveoli (Lovejoy et al., 1961 ) and/or changes in the lung mechanics (Cade et al. 1971). If non-ventilated areas give rise to the increas in residual volume in this study, they would not bereflected by the gas dilution method, where a decreases in residual lung volume would be expected. This indicates that changes in the mechanical properties of the lung, the chest wall or both are induced by $15-m e^{\omega}$ $\mathrm{PGF}_{2 a}$, in agreement with the findings of a rapick change in the lung mechanics induced by metha은 choline in asthmatic subjects (Cade et al., 1971) and with the findings of a decrease in elastic recoil in asthmatic patients (Gold, Kaufman, and Nadel $\frac{0}{0}$ 1967; Finucane and Colebatch, 1969).

Our findings of a redistribution of blood flow? towards the apex with no change in cardiac outpue 
could be caused by an increase in the pulmonary artery pressure, as has been shown during the infusion of $\mathrm{PGF}_{2 a}$ (Secher and Andersen, 1976). The more pronounced redistribution of ventilation than perfusion caused mismatching of ventilation and perfusion, as demonstrated by a fall in arterial oxygen tension. Our findings point to a change in perfusion being secondary to the more marked bronchoconstriction. The more pronounced effect of 15-me $\mathrm{PGF}_{2_{\alpha}}$ on lung base could be explained by a larger amount of prostaglandin being metabolized in that part of the lung where the blood flow is greatest. Another factor may be the lower oxygen tension in the basal alveoli in the sitting position (West, 1970) as it has been demonstrated that the effect of prostaglandin is accentuated by hypoxia in the isolated cat lung (Lonigro and Dawson, 1975).

\section{CONCLUSION}

It has been shown that 15 -me $\mathrm{PGF}_{2_{\alpha}}$ has induced airways obstruction, mainly confined to the dependent 'small airways'. The 15-me PGF $_{2 a}$ caused a response at the sites of larger and of 'small' airways, but the response of the larger airways was less pronounced and of shorter duration. The increased slope of the alveolar plateau and the decreased regional ventilation of the lower section, even after 60 minutes, indicated residual abnormality of the 'small airways'. It was demonstrated that $\mathrm{CV} \%$ was of no value as an indicator of the functional abnormality induced in the airways by the $15-$ me $\mathrm{PGF}_{2_{a}}$ as it became normal in spite of abnormalities in all the other measurements. The above-mentioned changes in the airways are consistent with an increase of smooth muscle tone in the small airways giving rise to the fall in $\mathrm{CV} \%$. This fall in $\mathrm{CV} \%$ could reflect physiological reality, ie, decreased tendency towards airway closure, or could be an artefact as the curvilinear take-off from the alveolar plateau makes the measurement of the closing point difficult. Therefore, the CV\% should not be used in cases of pathological increase of slope of the alveolar plateau. Our findings of an increase in closing capacity ( $\mathrm{CC} \%$ ) with no change in TLC is explained by the increase in residual volume, which means that the parameter $\mathrm{CC} \%$ gives no more information than measurement of residual volume. The detection of uneven distribution of alveolar ventilation, expressed as the slope of the alveolar plateau in the modified single breath nitrogen test, is therefore more sensitive than the conventional spirometric test.

As a significant degree of airways obstruction has been induced by $15-$ me $\mathrm{PGF}_{2_{a}}$, the drug should be used with caution for termination of pregnancy in women with cardiopulmonary disease.
REFERENCES

Alpert, J. S., Haynes, F. W., Knutson, P. A., Dalen, J. E., and Dexter, L. (1973). Prostaglandins and the pulmonary circulation. Prostaglandins, 3, 759.

Anders ən, L. H., Bö, G., Sundström, G., and Wranne, B. (1974). Closing volume: influence of extrabronchial factors. Review. Scandinavian Journal of Clinical and Laboratory Investigation, 34, 1.

Johansen, J. K., and Hyldebrandt, N. (1976) Pattern of regional pulmonary blood flow in mitral disease. British Heart Journal, 38, 573. and Rasmussen, F. V. (1975). The regional ventilation and perfusion as a function of the pressure in the left atrium. Distribution of pulmonary gas exchange. INSERM, 51, 299.

Ball, W. C., Jr., Stewart, P. B., Newsham, L. G. S., and Bates, D. V. (1962). Regional pulmonary function studied with Xenon ${ }^{133}$. Journal of Clinical Investigation, 41, 519.

Benson, M. K. and Mansell, A. (1975). Test of uneven ventilation. Difference between smokers and nonsmokers. Bulletin de Physio-pathologie Respiratoire, 11, $33 \mathrm{P}$.

, Newberg, L. A., and Jones, J. G. (1975). Nitrogen and bolus closing volumes: differences after histamine-induced bronchoconstriction. Journal of Applied Physiology, 38, 1088.

Buist, A. S. and Ross, B. B. (1973a). Predicted values for closing volumes using a modified single breath nitrogen test. American Review of Respiratory Disease, 107, 744.

and - (1973b). Quantitative analysis of the alveolar plateau in the diagnosis of early airway obstruction. American Review of Respiratory Disease, 108, 1078.

Cade, J. F., Woolcock, A. J., Rebuck, A. S., and Pain, M. C. F. (1971). Lung mechanics during provocation of asthma. Clinical Science, 40, 381.

Finucane, K. E. and Colebatch, H. J. H. (1969). Elastic behavior of the lung in patients with airway obstruction. Journal of Applied Physiology, 26, 330.

Gold, W. M., Kaufman, H. S., and Nadel, J. A. (1967). Elastic recoil of the lungs in chronic asthmatic patients before and after therapy. Journal of Applied Physiology, 23, 433.

Kadowitz, P. J., Joiner, P. D., and Hyman, A. L. (1974). Influence of prostaglandins $E_{1}$ and $F_{2 a}$ on pulmonary vascular resistance in the sheep. Proceedings of the Society for Experimental Biology and Medicine, 145, 1258.

Kubicek, W. G., Karnegis, J. N., Patterson, R. P., Witsoe, D. A., and Mattson, R. H. (1966). Development and evaluation of an impedance cardiac output system. Aerospace Medicine, 37, 1208.

Lonigro, A. J. and Dawson, C. A. (1975). Vascular responses to prostaglandin $F_{2 a}$ in isolated cat lungs. Circulation Research, 36, 706.

Lovejoy, F. W., Jr., Constantine, H., Flatley, J., Kaltreider, N., and Dautrebande, L. (1961). Measurement of gas trapped in the lungs during acute changes in airway resistance in normal subjects and in patients with chronic pulmonary disease. American Journal of Medicine, 30, 884. 
Luepker, R. V., Michael, J. R., and Warbasse, J. R. (1973). Transthoracic electrical impedance: quantitative evaluation of a non-invasive measure of thoracic fluid volume. American Heart Journal, 85, 83.

Mansell, A., Bryan, C., and Levison, H. (1972). Airway closure in children. Journal of Applied Physiology, 33, 711.

Oxhøj, H. and Bake, B. (1974). Measurement of closing volume with the single breath nitrogen method. Scandinavian Journal of Respiratory Diseases, 55, 320.

Piper, P. J. and Vane, J. R. (1971). The release of prostaglandins from lung and other tissues. Annals of the New York Academy of Sciences, 180, 363.

Rasmussen, F. V., Sølvsteen, P. C., and Andersen, L. H. (1975). Measurement of closing volumes by the single-breath nitrogen washout technique in an epidemiological study. Bulletin de Physio-pathologie Respiratoire, 11, 21 p.

Secher, N. J. and Andersen, L. H. (1976). Changes in the pattern of regional pulmonary blood flow after

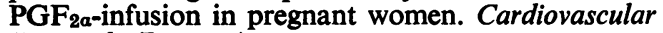
Research. (In press).

Shaw, J. O. and Moser, K. M. (1975). The current status of prostaglandins and the lungs. Chest, 68, 75.
Siegel, S.'(1956). Nonparametric Statistics for the Behave ioral Sciences, pp. 75-83. McGraw-Hill, New York.

Smith, A. P. (1973). The effects of intravenous infusion on graded doses of prostaglandins $F_{2 a}$ and $E_{2}$ on lung resistance in patients undergoing termination of pregnancy. Clinical Science, 44, 17.

Stanescu, D. C., Frans, A., and Brasseur, L. (1973). Acuteincrease of total lung capacity in asthma following histamine aerosols. Bulletin de Physio-pathologie. Respiratoire, 9, 523.

Teculescu, D. B., Pacuraru, R., and Popa, V. (1968) Effect of bronchoconstrictor aerosols on the alveolap plateau of the single breath $\mathrm{O}_{2}$ test. Thorax, 23, 628.

West, J. B. (1970). Ventilation/Bloodflow and Gas Exं change, 2nd edition, pp. 34-58. Blackwell, Oxford.

Woolcock, A. J., Rebuck, A. S., Cade, J. F., and Read, Jụ (1971). Lung volume changes in asthma measureof concurrently by two methods. American Review of Respiratory Disease, 104, 703.

Requests for reprints to: Dr. L. H. Andersen, Departmen of Clinical Physiology, Odense University Hospital, DK-5000, Odense, Denmark. 